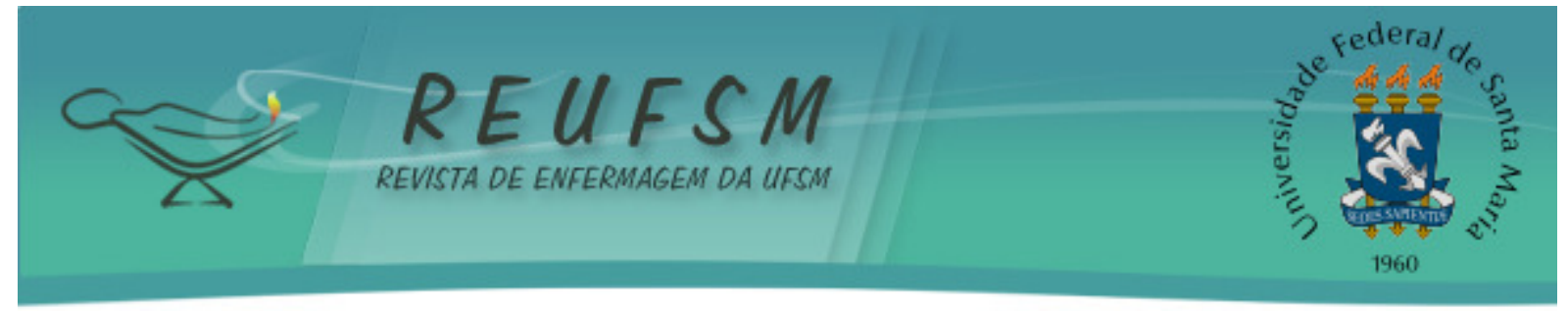

ARTIGO ORIGINAL

\title{
SOBRECARGA FINANCEIRA VIVENCIADA POR FAMILIARES CUIDADORES DE INDIVÍDUOS DEPENDENTES QUÍMICOS
}

\author{
FINANCIAL OVERLOAD EXPERIENCED BY FAMILY CAREGIVERS OF CHEMICAL \\ DEPENDENTS
}

\section{SOBRECARGA FINANCIERA EXPERIMENTADA POR LOS FAMILIARES CUIDADORES DE PERSONAS DEPENDIENTES QUIIMICAS}

\author{
Keity Laís Siepmann Soccol ${ }^{1}$ \\ Marlene Gomes Terra² \\ Danilo Bertasso Ribeiro ${ }^{3}$ \\ Sadja Cristina Tassinari de Souza Mostardeiro ${ }^{4}$ \\ Joze Karlem da Silva Teixeira ${ }^{5}$ \\ Valquíria Toledo Souto ${ }^{6}$ \\ Eliane Tavares da Silva ${ }^{7}$
}

Doi: $10.5902 / 2179769211264$

RESUMO: Objetivo: descrever as situações desencadeadoras de sobrecarga financeira vivenciada por familiares cuidadores de indivíduos dependentes químicos. Método: pesquisa exploratória, descritiva com abordagem qualitativa. Participaram deste estudo 11 familiares cuidadores de indivíduos dependentes químicos que frequentam um Centro de Atenção Psicossocial álcool e drogas. A coleta de dados ocorreu por meio de entrevista individual, aberta e gravada. Para a análise dos dados, adotou-se a Análise de Conteúdo do tipo temática. Resultados: a dependência química causa prejuízos e dificuldades financeiras para a família. Ainda, fragiliza as relações familiares e gera sobrecarga física e psíquica para o cuidador. Conclusão: o convívio com um indivíduo dependente químico influencia na situação econômica da família e repercute, deste modo, no relacionamento familiar e social, causando diferentes prejuízos para a família.

Descritores: Enfermagem; Saúde mental; Família; Transtornos relacionados ao uso de substâncias; Cuidadores.

ABSTRACT: Aim: to describe the circumstances that cause financial burden experienced by family caregivers of addicted individuals. Method: descriptive and exploratory qualitative research. The study included 11 family caregivers of addicted individuals attending a Psychosocial Care Center for alcohol and other drugs. The data were collected through individual interviews, which were open and recorded. For data analysis, the

\footnotetext{
${ }^{1}$ Enfermeira. Mestre em Enfermagem. Doutoranda em Enfermagem da Universidade Federal de Santa Maria. Santa Maria, RS, Brasil. E-mail: keitylais@hotmail.com

2 Professora Doutora em Enfermagem. Docente do Departamento de Enfermagem da Universidade Federal de Santa Maria. Santa Maria, RS, Brasil. E-mail: martesm@hotmail.com.br

${ }^{3}$ Enfermeiro. Mestre em Enfermagem. Doutorando em Enfermagem da Universidade Federal do Rio Grande do Sul. Porto Alegre, RS, Brasil. E-mail: danilobertasso@gmail.com

${ }^{4}$ Professora Doutora em enfermagem. Docente do Departamento de Enfermagem da Universidade Federal de Santa Maria. Santa Maria, RS, Brasil. E-mail: sadjasm@yahoo.com.br

${ }^{5}$ Enfermeira. Mestranda em Enfermagem da Universidade Federal de Santa Maria. Santa Maria, RS, Brasil. Email: jozekst@hotmail.com

${ }^{6}$ Enfermeira. Mestranda em Enfermagem da Universidade Federal de Santa Maria. Santa Maria, RS, Brasil. Email: valquiriatoledo@hotmail.com

7 Graduanda em Enfermagem da Faculdade Integrada de Santa Maria. Santa Maria, RS, Brasil. E-mail: elianesilvat@hotmail.com
} 


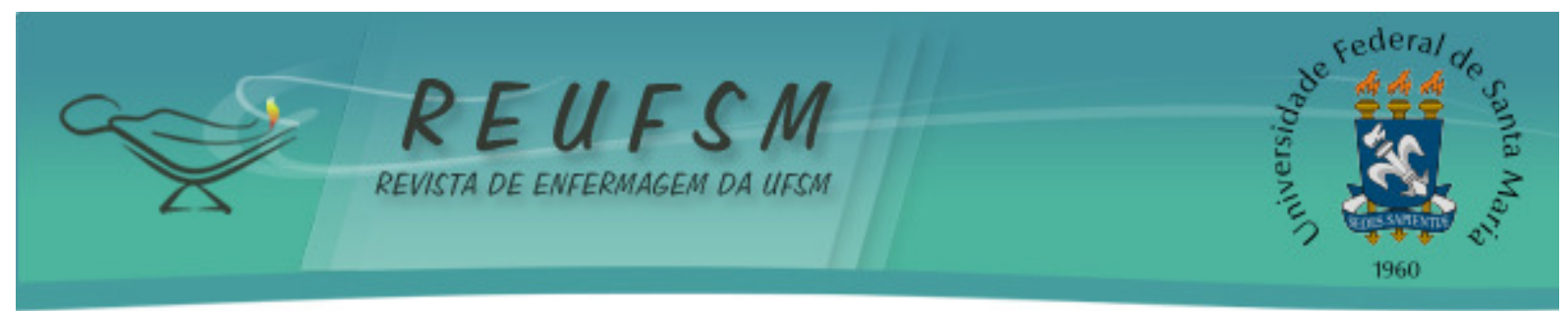

thematic Content Analysis was adopted. Results: addiction causes damage and financial difficulties for the family. Still, it jeopardizes family relationships and generates physical and psychological overloading for the caregiver. Conclusion: living together with a chemically dependent individual influences in the economic situation of the family and, thus, reflects in family and social relationships, causing different damages to the family. Descriptors: Nursing; Mental health; Family; Substance-related disorders; Caregivers.

RESUMEN: Objetivo: describir las circunstancias que causaron la sobrecarga financiera experimentada por los familiares cuidadores de personas adictas. Método: estudio cualitativo, exploratorio y descriptivo. En el estudio participaron 11 cuidadores familiares de personas que asisten a un Centro de Atención Psico-social a adictos al alcohol y drogas. Los datos fueron recolectados a través de entrevistas individuales, abiertas y registrados. Para el análisis de los datos, adoptamos el análisis de contenido del tipo temático. Resultados: la adicción causa daño y dificultades económicas para la familia. Además, fragiliza las relaciones familiares y genera carga física y psicológica para el cuidador. Conclusión: la convivencia con un dependiente químico influencia la situación económica de la familia y se refleja en las relaciones familiares y sociales, causando diversos perjuicios a la familia.

Descriptores: Enfermería; Salud mental; Familia; Trastornos relacionados con sustancias; Cuidadores.

\section{INTRODUÇÃO}

O consumo de drogas é uma prática humana universal e milenar. Desde os tempos mais remotos a humanidade vem utilizando as drogas durante cerimônias religiosas, lazer ou como finalidade curativa. ${ }^{1}$ Entretanto, no decorrer dos séculos, o uso de drogas pelos indivíduos acentuou-se, levando-os ao abuso, à dependência química dessas substâncias e à criminalidade. Atualmente, $\mathrm{o}$ abuso de drogas vem se tornando uma prática comum no cotidiano, o que está preocupando a sociedade. Esta tem debatido o tema drogas em busca de soluções e de enfrentamento desta problemática social e de saúde. ${ }^{2}$

A dependência química é caracterizada como um conjunto de sintomas cognitivos, comportamentais e psicológicos, devido ao uso de drogas, que implica na necessidade de repetidas doses da droga para que o indivíduo que a utiliza possa se sentir bem e evitar sensações ruins. ${ }^{3}$ Pode-se dizer que a mesma atinge as pessoas de distintas maneiras. Por um lado, afeta a sua saúde e, por outro, ocasiona impactos negativos na rede de relacionamento interfamiliar dos usuários, por diferentes razões, em distintos momentos ${ }^{4-5}$, intervindo no seu modo de vivenciar e lidar com o cotidiano. ${ }^{2}$

Neste sentido, pode-se afirmar que a dependência química compromete o cotidiano familiar afetando a economia, as relações no trabalho e a sociabilidade. Ainda, é importante compreender que os malefícios ocasionados pelo uso da droga não podem ser compreendidos restritamente aos danos biológicos no indivíduo, mas, é necessário considerar o contexto cultural que envolve o seu consumo. ${ }^{6}$

Os indivíduos que vivenciam esta problemática no seio da família, por estarem diretamente ligados às consequências do uso de drogas, se tornam vítimas desse mundo de sofrimento, dificuldades, indecisões e desilusões, tornando-se vulneráveis a emoções como compaixão, abandono, tristeza e raiva. ${ }^{7}$ Assim, cuidar de um indivíduo dependente químico não é uma tarefa fácil para os familiares cuidadores e para a sociedade. ${ }^{2}$

Neste estudo entende-se a família como uma unidade que cuida de seus membros, sendo considerada como o principal agente socializador dos seus componentes, assim como a responsável pelo atendimento de suas necessidades básicas. ${ }^{8}$ É importante lembrar, no que 


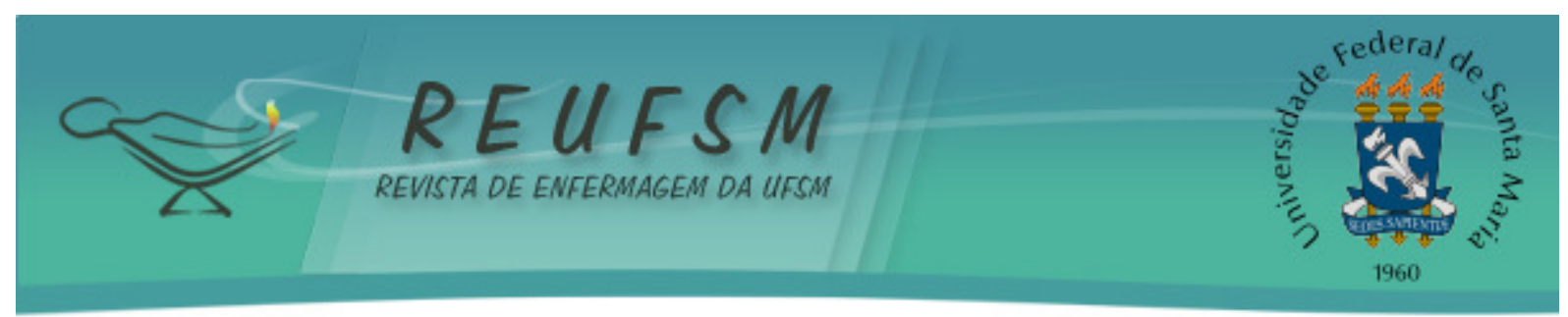

tange ao impacto da dependência química, que todos são atingidos, especialmente os familiares, pois estes estão mais próximos e, geralmente, se responsabilizam pelos entes em adoecimento. ${ }^{9}$

As consequências da dependência química ocasionam a desestruturação da vida familiar, social e profissional. As tarefas extras e a convivência com comportamentos que podem ser indevidos são situações que causam desgaste físico, mental, emocional e social. ${ }^{10}$

Diante dessas situações advindas da dependência química, salienta-se a sobrecarga financeira com a qual os familiares cuidadores passam a lidar devido a gastos exagerados do usuário para adquirir a droga. Conforme dicionário da língua portuguesa ${ }^{11}$, o termo sobrecarga refere-se a uma carga excessiva. Já na língua inglesa, a palavra burden vem sendo utilizada para descrever os aspectos negativos relacionados ao cuidado de indivíduos doentes equivalendo a termos como fardo, impacto, sobrecarga e interferência. ${ }^{12}$ Neste estudo dá-se ênfase às cargas excessivas de ordem financeira que a família pode ser levada a assumir ao cuidar de um indivíduo dependente químico.

A sobrecarga financeira é desencadeadora de situações estressantes e desgaste em toda a família. Frente a isso, entende-se que a enfermagem tem compromisso de incluir a família no cuidado, fornecendo apoio emocional para que se sintam preparados e fortalecidos para atuar nesse processo, além de contribuir para direcionar a tomada de decisões que minimizem as repercussões financeiras para a família.

Este estudo faz-se relevante à medida que busca compreender a dinâmica dessas famílias diante das sobrecargas as quais estão suscetíveis. Ainda, justifica-se que a maioria dos estudos que abordam a temática da sobrecarga familiar têm descrito a experiência de familiares de indivíduos com transtornos psiquiátricos ${ }^{8,13-15}$ revelando a carência de conhecimento acerca destas situações de sobrecarga no contexto de famílias que possuem entre os seus membros indivíduos dependentes químicos.

Com vistas a atender essas demandas, tem-se como questão de pesquisa: quais as situações desencadeadoras de sobrecarga financeira no cuidado ao indivíduo dependente químico? E, como objetivo, descrever as situações desencadeadoras de sobrecarga financeira vivenciada por familiares cuidadores de indivíduos dependentes químicos.

\section{MÉTODO}

Este estudo se constituiu de um recorte de um banco de dados de um trabalho de conclusão de curso. ${ }^{16}$ Seguiu os princípios e diretrizes da Resolução $n^{\circ} 196 / 96$ do Conselho Nacional de Saúde ${ }^{17}$, aprovado pelo Comitê de Ética em Pesquisa da Universidade Federal de Santa Maria, sob o n 0159.0.243.000-11, em 9 de agosto de 2011.

Trata-se de uma pesquisa qualitativa do tipo exploratória e descritiva, realizada em um Centro de Atenção Psicossocial - álcool e drogas (CAPS ad), localizado em um município do estado do Rio Grande do Sul (RS). Como sujeitos foram considerados 11 familiares de indivíduos dependentes químicos, convidados intencionalmente a participarem do estudo. Estabeleceu-se como critérios de inclusão: ser familiar frequentador do grupo de familiares do CAPS ad; familiar com parentesco de primeiro e segundo grau ou cônjuge; apenas um familiar por dependente químico. Foram excluídos os familiares de dependentes químicos que tinham idade inferior a 18 anos.

A coleta dos dados ocorreu por meio de entrevista individual e aberta, com gravação digital, no período de agosto e setembro de 2011. Foi utilizada uma sala disponibilizada pelos profissionais do CAPS ad, buscando garantir a privacidade e o sigilo das informações dos participantes. Por se tratar de pesquisa com seres humanos, os familiares assinaram o Termo de Consentimento Livre e Esclarecido (TCLE), em duas vias, no qual ficavam cientes do objetivo do estudo, bem como de que os pesquisadores iriam 


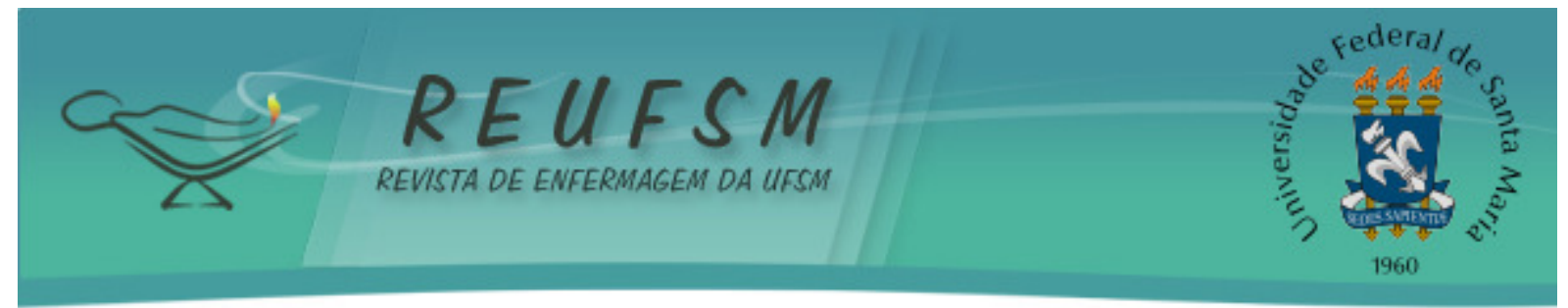

preservar o seu anonimato utilizando a letra ' $F$ ' por ser a letra inicial da palavra família, seguida do número de ordem das entrevistas (F1, F2, F3, e assim sucessivamente).

A entrevista contemplava a caracterização sociodemográfica dos sujeitos com questões relativas ao parentesco do familiar com o indivíduo dependente químico, procedência, e idade. Para desencadear a entrevista questionou-se: como é para você cuidar do seu familiar dependente de álcool e outras drogas? No entanto, outras perguntas poderiam ser realizadas caso fossem necessárias. Quando as informações começaram a se repetir, as entrevistas foram cessadas por considerar-se que houve saturação dos dados, ou seja, ausência de novos elementos para responder ao objetivo do estudo, sendo as respostas satisfatórias para a compreensão das categorias temáticas. ${ }^{18}$

As entrevistas foram transcritas $e$ os textos foram lidos individual e exaustivamente, visando colocá-los em certa ordem, sendo analisados pela técnica de análise de conteúdo, na modalidade temática, conforme a proposta operativa de Minayo. ${ }^{18}$ Essas leituras possibilitaram a classificação e o registro de unidades temáticas ou de significados. Na sequência, houve a exploração do material e, posteriormente, realizou-se a codificação e a enumeração das unidades de significado que foram organizadas e classificadas em categorias. Com isto foi possível aproximar-se daquilo que foi informado pelos familiares cuidadores entrevistados e, aos poucos, foi emergindo o que era central nas mensagens. Ainda, no decorrer desse processo, a revisão de literatura foi utilizada como base para a organização, as análises e as interpretações.

\section{RESULTADOS E DISCUSSÃO}

Dos 11 familiares entrevistados, havia um homem e dez mulheres, com idades entre 32 e 85 anos de idade. Quanto a relação de parentesco existente, entrevistou-se um pai, cinco mães e cinco cônjuges. Considerando suas situações ocupacionais, havia dois trabalhadores, quatro aposentados e cinco do lar/desempregados.

Das entrevistas com os familiares cuidadores emergiram duas categorias: o sustento da dependência química: repercussões para a família; e, dificuldades financeiras enfrentadas pela família. A seguir são descritas tais categorias.

\section{O sustento da dependência química: repercussões para a família}

Esta categoria evidencia a repercussão da dependência química não somente para o usuário de drogas, mas também para os familiares que convivem com ele em seu cotidiano. Os familiares são afetados na medida em que a dependência química do usuário evolui trazendo, além de implicações psicossociais, prejuízos financeiros diante da necessidade do usuário em sustentar o seu consumo de drogas:

Cada vez que ele vinha era dinheiro, dinheiro, dinheiro, e eu não dava dinheiro, ele pegava o que ele podia pegar para vender, para trocar. Ele estava me roubando as coisas de dentro de casa. (F1)

Ao se dedicar ao cuidado do seu familiar dependente químico, no cotidiano, o familiar cuidador experimenta situações de impotência, pois o dinheiro disponibilizado nunca é suficiente. Quando isso acontece, os utensílios da casa passam a representar fontes de renda para o indivíduo dependente. Assim, a falta de condições financeiras para sustentar o uso constante de droga pode ocasionar o envolvimento com atividades ilícitas, como roubos, tráficos e assaltos, interferindo de maneira negativa na saúde e funcionamento social do usuário ${ }^{19}$ e de sua família. As drogas destroem a vida do usuário, e ele acaba vendendo ou 


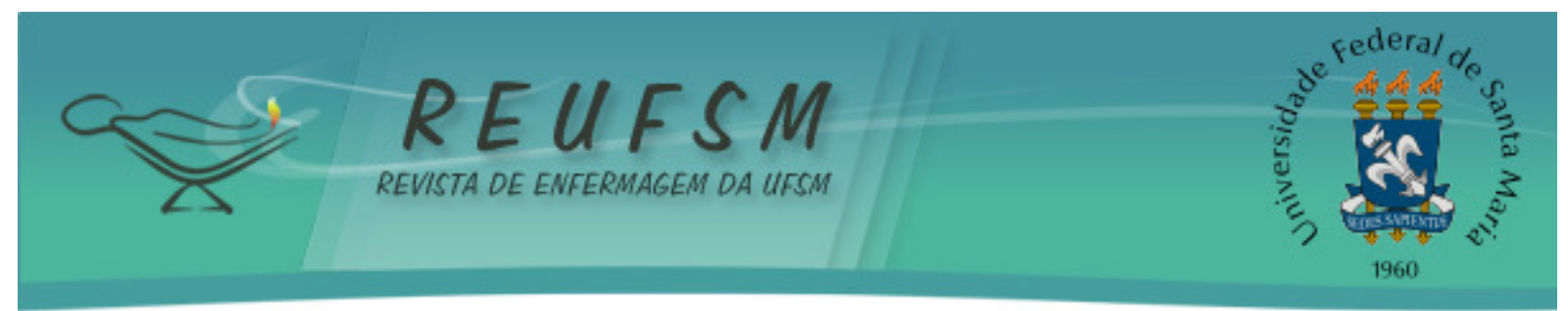

trocando tudo o que tem para adquiri-las. ${ }^{20}$ Diante do desejo incontrolável de usar a droga, o dependente químico pode passar a vender seus próprios pertences para financiar sua dependência ou, quando esgotados esses recursos, roubar da própria família:

Pegava o que tinha pela frente, levava para trocar. Na hora tu não sentes falta, dá falta depois...roupa, casaco, pegava todas essas coisas, nossa! Ele também arrombou a casa do irmão. Vários objetos roubaram! (F4)

Ele não pára! E ele quer dinheiro, e vende tudo o que ele tem. Ele me deixou a casa pelada. Só não levou a geladeira e o fogão. Mas ventilador, essas coisas miúdas, prato, talher, toalha de mesa, toalha de banho, tudo ele vendeu. Meus lençóis, a minha roupa todinha ele carregou. (F8)

Sabe-se que quando um dependente químico fica um tempo prolongado sem usar a droga, ele começa a apresentar sinais de fissura, que se apresenta como uma vontade intensa e incontrolável de consumir a droga. Nessas situações, o indivíduo age impulsiva e inconsequentemente, chegando a praticar atos de furto. ${ }^{19}$ No ambiente familiar, o roubo pode causar desavenças, perda de confiança e ampliar as dificuldades de relacionamento entre esses familiares.

Diante dos roubos que acontecem em casa, os familiares sentem-se fragilizados ${ }^{21}$, e descrevem a situação como geradora de sofrimento, como também pode ser evidenciado a seguir:

Ele aprontou tanta coisa! Entrou na minha casa, que tem uma despensa, e levou tudo, desde alimentação até esses negócios de enlatado, café, biscoito...não tinha coisa mais dolorosa! (F3)

Percebe-se nesse depoimento que o familiar observa essas situações no seu lar numa atitude de passividade. Essa circunstância permite pensar sobre a violência a qual esses familiares ficariam expostos ao tentar impedir a retirada de objetos da sua casa. Assim, emocionalmente e fisicamente, o familiar torna-se incapaz de impedir esses furtos, já que em alguns casos os dependentes químicos podem tornar-se agressivos, violentando a própria família para conseguir recursos para comprar a droga. Nesse contexto, evidências apontam para a crescente violência, morte e destruição familiar em decorrência do abuso de drogas. ${ }^{21-22}$

Devido ao estilo de vida sem perspectiva de um novo recomeço, no decorrer dos anos, o usuário de drogas se adapta a essa condição apesar dos riscos de morte, assim como é comum o seu envolvimento com o tráfico ou em outras atividades ilícitas para conseguir manter sua dependência. ${ }^{23}$ Nesse contexto, o cuidado ao usuário desorganiza a rotina e os compromissos dos familiares cuidadores, acarretando fatores de estresse, com os quais necessitam aprender a lidar. ${ }^{12}$

Para além do sofrimento pela perda dos bens materiais, que foram conquistados e adquiridos ao longo da sua vida, os familiares sofrem, principalmente, ao verem o seu dependente químico debilitado e exposto a todo tipo de risco devido à dependência de drogas. Essas questões demonstram a necessidade de inserir esse indivíduo em um tratamento para recuperação de dependentes químicos, a fim de que perceba as repercussões de seu comportamento ocasionado pelas drogas na sua vida e na vida de seus familiares. 


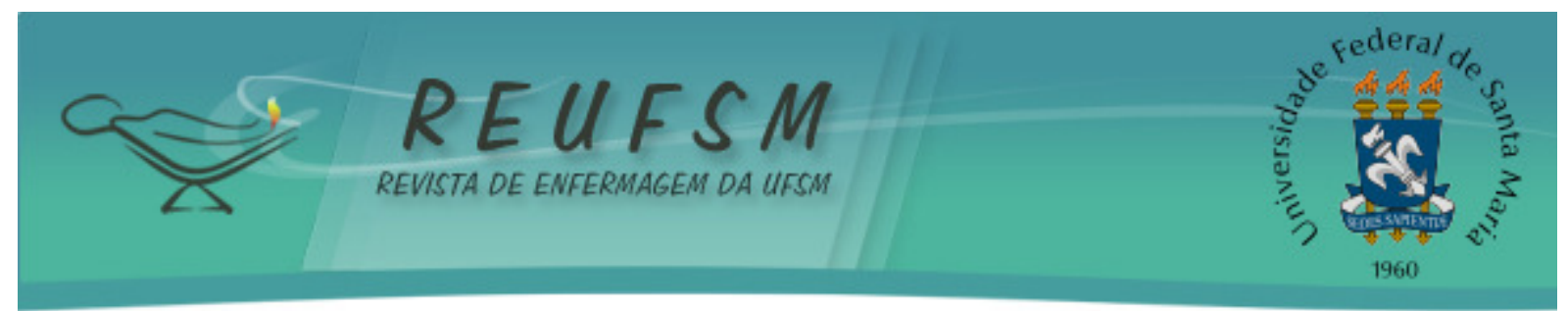

Porém, cabe destacar aqui, que não são todos os indivíduos dependentes químicos que realizam essas atividades ilícitas para a obtenção da droga. Nosso objetivo não é rotular o dependente químico, mas sim mostrar o quanto o seu comportamento, quando alterado, pode afetar a dinâmica da família e repercutir na sociedade.

\section{Dificuldades financeiras enfrentadas pela família}

Essa categoria aborda as dificuldades e as consequências financeiras que os familiares cuidadores enfrentam, em diversas situações, no seu cotidiano de cuidado ao dependente químico. Isso pode ser percebido quando o dependente passa a não mais fornecer auxílio financeiro no lar, utilizando toda a sua renda para custear as drogas:

Ele botava todo o dinheiro em bebida. Ele trabalhava só para beber. Às vezes, não tinha nem um arroz para comer. Daí eu que saía no outro dia para arrumar uma faxina ou ia lá na minha mãe e no meu pai pedir ajuda. (F6)

Evidencia-se que as famílias de dependentes químicos, em seu cotidiano, podem vivenciar dificuldades financeiras que permeiam por necessidades básicas de existência, como a alimentação. Em virtude disso, uma alternativa encontrada por essas famílias é solicitar algum tipo de auxílio para as pessoas mais próximas, como amigos, vizinhos e até mesmo para outros parentes que possuem uma condição financeira melhor. Além disso, as famílias que estão economicamente vulneráveis podem ter sua situação financeira agravada, pois vivenciam um processo complexo, que exige uma nova estrutura nas relações de trabalho, nas inter-relações e no orçamento familiar. ${ }^{14}$

As despesas de manutenção no lar também recaem sobre o familiar cuidador, como evidenciado no trecho a seguir:

Ele nunca soube o que é pagar uma conta de água, a conta de luz. Ele nunca soube o imposto do terreno, então depende de mim para tudo. (F9)

Evidencia-se que, geralmente, as responsabilidades com despesas do lar recaem sobre um único familiar, fazendo com que essa situação o sobrecarregue financeiramente. O familiar cuidador precisa suprir o papel que o dependente químico não está conseguindo suprir no momento, e essa situação pode fazer com que a família enfrente perdas em sua qualidade de vida.

Além dos gastos que o familiar possui para atender as necessidades básicas da família, por ter entre seus membros um dependente químico, também tem acrescidos gastos para a manutenção do seu cuidado, que envolve consultas, internações e tratamento medicamentoso:

Desde clínica particular ele botou pagando caro por dia... fizemos de tudo! (F3)

O cuidado realizado pelo familiar é um fazer quase sempre solitário e sem descanso, podendo levar a um comprometimento em sua vida, repercutindo tanto no aspecto físico como no psíquico, bem como ocasionando dificuldades financeiras. ${ }^{24}$ Assim, conviver com uma doença no âmbito familiar é desgastante para a família e implica em compreender e lidar com comportamentos distintos. ${ }^{14}$ 


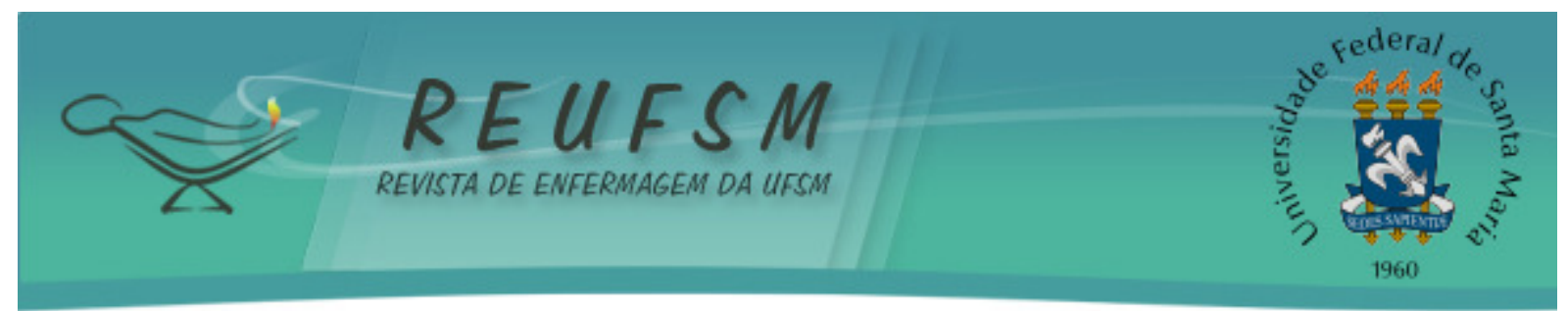

Também se percebe que os familiares cuidadores preocupam-se diante das demandas de saúde do dependente químico e por não saberem mais de onde obter recursos financeiros para a manutenção do tratamento:

Ele já teve sete internações. Fui levar ele [na fazenda], no outro dia estava de volta, e não quis ficar. A gente não tinha dinheiro. Daí a gente fez uma vaquinha ... Demos o dinheiro, no outro dia ele não quis ficar. (F4)

Com essa internação de lá passei trabalho, porque eu tinha que dar tudo que ele precisava lá. Três vezes ele adoeceu, ligavam para cá, que eles estavam mandando ele e cada vez que ele vinha tinha que pagar tudo, pagar almoço e passagem, não tinha de onde tirar! Sabe o que é tu ficares sem um centavo no bolso, sem nada? Pedir emprestado para os outros? Era só eu para tudo, não foi fácil não!(F9)

As evidências dos problemas ocasionados pelas drogas causam um significativo impacto na família, mesmo quando os dependentes químicos estão internados. Com isso, destaca-se a necessidade de compreender o significado da dependência química no cotidiano dos cuidadores. ${ }^{6} \mathrm{~A}$ assistência e os cuidados cotidianos prestados aos indivíduos, a frequência de supervisão aos seus comportamentos problemáticos e as perturbações na rotina, na vida social e profissional dos familiares, além dos custos financeiros gerados especificamente pelo ato de cuidar, causam uma importante sobrecarga para os familiares cuidadores. $^{15}$ Além das dificuldades financeiras com 0 tratamento, outra situação agravante é a dívida do dependente químico com os traficantes:

lam matar ele na cadeia e eu fui lá para ver se era verdade, daí o agente que me atendeu disse que era verdade. "Se ele não pagar os traficantes e a dívida dele vão matar o seu filho"! (F4)

Diante do medo de que algo possa acontecer com o familiar dependente químico, a família acaba pagando as dívidas com os traficantes e arcando com mais essa sobrecarga financeira. Além disso, há uma preocupação com a ameaça de traficantes para com os outros familiares, além do dependente químico, caso a dívida não seja paga.

Assim, esta categoria evidenciou que são muitas as dificuldades financeiras vivenciadas pelas famílias de dependentes químicos. Faz-se relevante lembrar que a família é fundamental para a manutenção da saúde e a qualidade de vida do dependente químico, por isso, essa também precisa ser inserida no contexto das estratégias de atenção dos profissionais de saúde, pois sofre de uma sobrecarga para cuidar de seu familiar dependente químico, vivenciando diversas dificuldades. ${ }^{5}$

Essas situações de prejuízos e dificuldades financeiras podem ocasionar um adoecimento em toda a família, constatando-se a necessidade de um olhar mais atento dos profissionais da enfermagem e da área da saúde para tentar minimizar esses danos psicológicos, físicos e sociais.

\section{CONCLUSÃO}

Este estudo evidenciou que o convívio com um dependente químico influencia na situação econômica da família, gerando aos familiares cuidadores uma sobrecarga financeira, e repercutindo, deste modo, no relacionamento familiar, causando diferentes prejuízos para a 


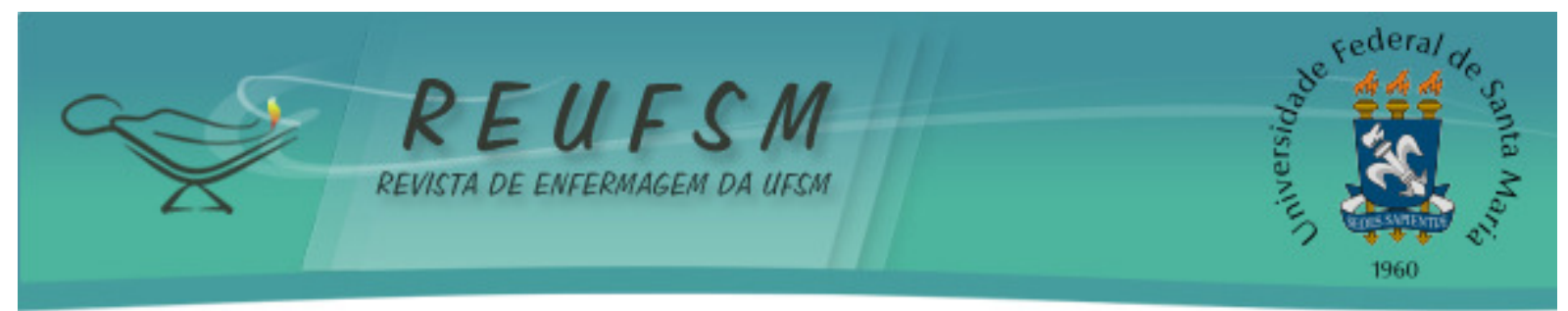

família. Logo, pode-se afirmar que a dependência química afeta a vida de todos os integrantes da família, de diferentes formas, que vão além dos prejuízos financeiros.

Este estudo aponta para a necessidade da enfermagem aproximar-se das famílias que possuem indivíduos dependentes químicos, de conhecer suas crenças, valores, cultura e condições econômicas para que possa construir junto às famílias um plano de cuidado direcionado às individualidades de cada situação.

Assim, torna-se imprescindível um olhar atento da enfermagem como cuidadora, pois esta necessita compreender todas as dimensões que envolvem esta temática, não somente acerca da sobrecarga financeira. 0 ser humano é biopsicossocial, e qualquer alteração em uma dessas estruturas acaba interferindo nas outras, ou seja, a sobrecarga financeira reflete diretamente na saúde mental e física desse familiar cuidador. Além disso, é relevante que os profissionais que atuam na área da saúde, dentre esses o enfermeiro, se qualifiquem, para assim atuar de maneira efetiva frente a esta problemática, pois o dependente químico e seus familiares ainda são estigmatizados por profissionais da área da saúde e excluídos socialmente.

Este estudo também aponta para a necessidade de uma melhor compreensão da dinâmica das famílias que possuem indivíduos dependentes químicos, assim como conhecer as estratégias de enfrentamento que por elas vêm sendo utilizadas. Há que se levar em consideração a história de vida dessas famílias para assim poder compreendê-las.

\section{REFERÊNCIAS}

1. Gabatz RIB, Johann M, Terra MG, Padoin SMM, Silva AA, Brum JL. Percepção do usuário sobre a droga em sua vida. Esc Anna Nery Rev Enferm [Internet]. 2013 [acesso em 2013 out 20]; 17(3):520-5. Disponível em: http://www.scielo.br/pdf/ean/v17n3/1414-8145-ean-1703-0520.pdf.

2. Cavalcante LP, Falcão RST, Lima HP, Marinho AM, Macedo JQ, Braga VAB. Rede de apoio social ao dependente químico: ecomapa como instrumental na assistência em saúde. Rev Rene [Internet]. 2012 [acesso em 2013 ago 12];13(2):321-31.Disponível em: http://www.revistarene.ufc.br/revista/index.php/revista/article/view/215.

3. Secretaria Nacional de Políticas sobre Drogas (SENAD). Glossário de álcool e drogas. Tradução e notas de J.M. Bertolote. Brasília: Secretaria Nacional de Políticas sobre Drogas; 2010.

4. Silva LHP, Borba LO, Paes MR, Guimarães AN, Mantovani MF, Maftun MA. Perfil dos dependentes químicos atendidos em uma unidade de reabilitação de um hospital psiquiátrico. Esc Anna Nery Rev Enferm [Internet]. 2010 [acesso em 2013 ago 12];14(3):585-90. Disponível em: http://www.scielo.br/pdf/ean/v14n3/v14n3a21.pdf.

5. Soccol KLS, Terra MG, Girardon-Perlini NMO, Ribeiro DB, Silva CT, Camillo LA. O cuidado familial ao indivíduo dependente de álcool e outras drogas. Rev Rene [Internet]. 2013 [acesso em 2013 set 25];14(3):549-57. Disponível em: http://www.revistarene.ufc.br/revista/index.php/revista/article/view/1104.

6. Santos ECV, Martin D. Cuidadoras de pacientes alcoolistas no município de Santos, SP, Brasil. Rev Bras Enferm [Internet]. 2009 [acesso em 2013 set 25];62(2):194-9. Disponível em: http://www.scielo.br/scielo.php?pid=S0034-71672009000200004\&script=sci_arttext.

7. Ferreira Filha MO, Sá ANP, Rocha IA, Silva VCL, Souto CMRM, Dias MD. Alcoolismo familiar: estratégias de enfrentamento das idosas usuárias da terapia comunitária. Rev 


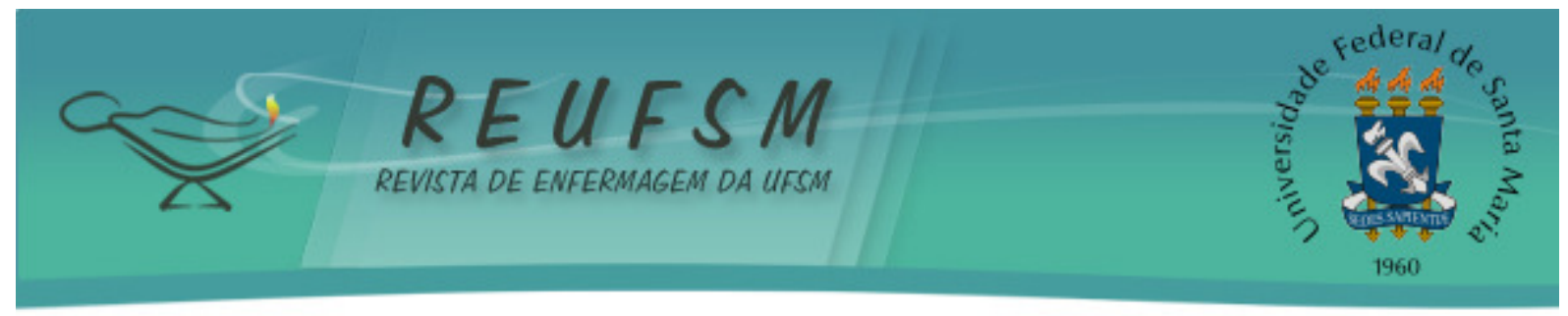

Rene [Internet]. 2012 [acesso em 2013 ago 12];13(1):26-35. Disponível em: http://www.revistarene.ufc.br/revista/index.php/revista/article/view/13.

8. Elsen I, Souza AIJ, Marcon SS. Enfermagem à família: dimensões e perspectivas. Maringá(PR): Eduem; 2011.

9. Hiller M, Bellato R, Araújo LFS. Cuidado familiar à idosa em condição crônica por sofrimento psíquico. Esc Anna Nery [Internet]. 2011 [acesso em 2013 ago 11];15(3):542-9. Disponível em: http://www.scielo.br/scielo.php?pid=S1414$81452011000300015 \&$ script=sci_arttext.

10. Zanatta $A B$, Garghetti FC, Lucca SR. O centro de atenção psicossocial álcool e drogas sob a percepção do usuário. Rev Baiana Saúde Pública [Internet]. 2012 [acesso em 2013 out 21];36(1):225-37. Disponível em: http://files.bvs.br/upload/S/01000233/2012/v36n1/a3011.pdf.

11. Weiszflog $W$, editor. Michaelis: moderno dicionário da língua portuguesa: Melhoramentos. $1^{\text {a }}$ ed. São Paulo; 2004. 2280 p.

12. Campos PHF, Soares CB. Representação da sobrecarga familiar e adesão aos serviços alternativos em saúde mental. Psicol Rev [Internet]. 2005 [acesso em 22 ago 2013];11(18):219-37. Disponível em: http://periodicos.pucminas.br/index.php/psicologiaemrevista/article/view/233.

13. Almeida MM, Schal VT, Martins AM, Modena CM. Sobrecarga de cuidadores de pacientes com esquizofrenia. Rev Psiquiatr Rio Gd Sul [Internet]. 2010 [acesso em 2013 out 18];32(3):73-9. Disponível em: http://www.scielo.br/pdf/rprs/2010nahead/1312.pdf.

14. Borba LO, Schwartz E, Kantorski LP. A sobrecarga da família que convive com a realidade do transtorno mental. Acta Paul Enferm [Internet]. 2008 [acesso em 2013 set 26];21 (4):588-94. Disponível em: http://www.scielo.br/pdf/ape/v21n4/a09v21n4.pdf.

15. Barroso SM, Bandeira M, Nascimento E. Fatores preditores da sobrecarga subjetiva de familiares de pacientes psiquiátricos atendidos na rede pública de Belo Horizonte, Minas Gerais, Brasil. Cad Saude Publica [Internet]. 2009 [acesso em 2013 out 2];25(9):1957-68. Disponível em: http://www.scielo.br/scielo.php?pid=S0102311X2009000900010\&script=sci_arttext.

16. Soccol KLS. O cuidado familial ao indivíduo dependente de álcool e outras drogas na percepção da família [monografia]. Santa Maria: Universidade Federal de Santa Maria; 2011. 50 p.

17. Ministério da Saúde (Brasil). Conselho Nacional de Saúde. Resolução CNS $n^{a} 196$, de 10 de outubro de 1996. Aprova diretrizes e normas regulamentadoras de pesquisa envolvendo seres humanos. Brasília (DF): Ministério da Saúde; 1996.

18. Minayo MCS. O desafio do conhecimento: pesquisa qualitativa em saúde. $10^{a}$ ed. São Paulo: Hucitec; 2010.

19. Oliveira LG, Nappo AS. Caracterização da cultura do crack na cidade de São Paulo: padrão de uso controlado. Rev Saúde Pública [Internet]. 2008 [acesso em 2013 out 25];42(4):664-71. Disponível em: http://www.scielo.br/scielo.php?pid=S003489102008005000039\&script=sci_arttext.

20. Gabatz RIB, Schmidt AL, Terra MG, Padoin SMM, Silva AA, Lacchini AJB. Percepção dos usuários de crack em relação ao uso e tratamento. Rev Gaucha Enferm [Internet]. 2013 


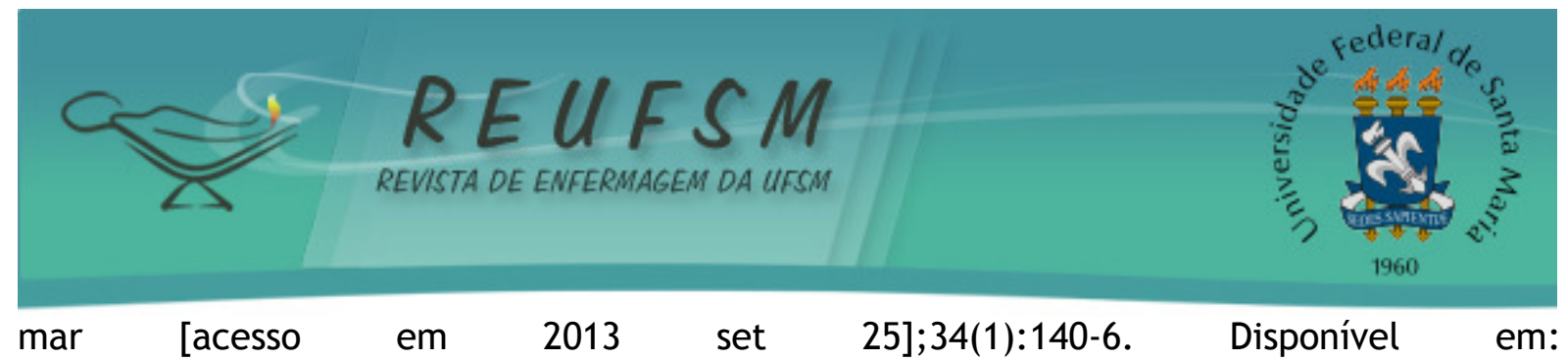

http: / /www.scielo.br/scielo.php?pid=S1983-14472013000100018\&script=sci_arttext.

21. Nonticuri AR. As vivências de adolescentes e jovens com o crack e suas relações com as políticas sociais protetoras neste contexto [dissertação]. Pelotas (RS): Universidade Católica de Pelotas; 2010.

22. Siqueira DF, Moreschi C, Pozzobon L, Vedoin PC, Walter RR, Sá RGC. Adolescente usuário de crack: relato de experiência. Rev Enferm UFSM [Internet]. 2012 [acesso em 2013 nov 2];2(2):456-63. Disponível em: http://cascavel.ufsm.br/revistas/ojs2.2.2/index.php/reufsm/article/view/3045.

23. Ribeiro LA, Sanchez ZM, Nappo SA. Estratégias desenvolvidas por usuários de crack para lidar com os riscos decorrentes do consumo de drogas. J Bras Psiquiatr [Internet]. 2010 [acesso em 2013 set 26];59(3):210-21. Disponível em: http://www.scielo.br/pdf/jbpsiq/v59n3/a07v59n3.pdf.

24. Beuter M, Rossi JR, Neves ET, Brondani CM. A sobrecarga do familiar no cuidado domiciliar. Rev Enferm UFPE on line [Internet]. 2009 [acesso em 2013 set 26];3(3):687-93. Disponível em: http://www.revista.ufpe.br/revistaenfermagem/index. php/revista/article/viewArticle/181.

Data de recebimento: $02 / 11 / 2013$

Data de aceite: $01 / 08 / 2014$

Contato com autor responsável: Keity Laís Siepmann Soccol

Endereço postal: Avenida Roraima, nํ 1000, prédio 26, sala 1445 - Camobi, Santa Maria RS, 97105-900

E-mail: keitylais@hotmail.com 